\title{
What has comprehensive HIV/AIDS knowledge got to do with HIV testing among men in Kenya and Mozambique? Evidence from Demographic and Health Surveys
}

\author{
Eugene Budu ${ }^{1}$, Abdul-Aziz Seidu ${ }^{1,2,3 *}$ (D), Ebenezer Kwesi Armah-Ansah ${ }^{1}$, Aliu Mohammed ${ }^{4}(\mathbb{D}$, \\ Collins $\mathrm{Adu}^{5}$, Edward Kwabena Ameyaw ${ }^{6}$ and Bright Opoku Ahinkorah ${ }^{6}$
}

\begin{abstract}
${ }^{1}$ Department of Population and Health, University of Cape Coast, Ghana, ${ }^{2}$ College of Public Health, Medical and Veterinary Services, James Cook University, Australia, ${ }^{3}$ Department of Estate Management, Takoradi Technical University, Ghana, ${ }^{4}$ Department of Health, Physical Education and Recreation, University of Cape Coast, Ghana, ${ }^{5}$ Department of Health Promotion, Education and Disability Studies, Kwame Nkrumah University of Science and Technology, Kumasi, Ghana and ${ }^{6}$ School of Public Health, Faculty of Health, University of Technology Sydney, Australia

${ }^{*}$ Corresponding author. Email: abdul-aziz.seidu@stu.ucc.edu.gh
\end{abstract}

(Received 1 February 2021; revised 15 April 2021; accepted 15 April 2021; first published online 08 June 2021)

\begin{abstract}
People living with undiagnosed HIV are big contributors to the transmission of the virus. Although measures have been made to scale up HIV prevention and voluntary counselling and testing in sub-Saharan Africa, testing coverage remains low in many sub-Saharan African countries, including Mozambique and Kenya, where most people live with HIV/AIDS. Studies have shown that, in most countries in sub-Saharan Africa, men are less likely to test for HIV compared with women. This study examined the relationship between comprehensive HIV/AIDS knowledge and HIV testing among men in Kenya and Mozambique. Data were from the men's recode file of the Demographic and Health Surveys of Mozambique and Kenya. Binary logistic regression models were generated and the results presented as crude odds ratios (cOR) and adjusted odds ratios (aOR). The prevalences of HIV testing in Kenya and Mozambique were $80.1 \%$ and $46.7 \%$, respectively. Men in Mozambique who had comprehensive HIV/AIDS knowledge ( $\mathrm{aOR}=1.26$, CI: $1.07-1.47)$ were more likely to test for HIV compared with their counterparts who had no comprehensive HIV/AIDS knowledge. In Kenya, men who had comprehensive HIV/AIDS knowledge ( $\mathrm{aOR}=1.23$, CI: 1.09-1.39) were more likely to test for HIV compared with their counterparts who had no comprehensive HIV/AIDS knowledge. This study found a statistically strong significant association between comprehensive HIV/AIDS knowledge and HIV testing among men in Kenya and Mozambique. To improve HIV testing rate among men, it is important that interventions are geared towards improving men's comprehensive HIV/AIDS knowledge, perhaps by expanding HIV/ AIDS education programmes and campaigns. This could improve HIV testing rates and ensure the realization of the global HIV/AIDS target of 95-95-95 by the year 2030 .
\end{abstract}

Keywords: HIV testing; Kenya; Mozambique

\section{Introduction}

The world has seen a significant reduction in the burden of new infections of HIV since the beginning of the 21st century (UNAIDS, 2015a). The virus has affected more than 76 million people, with almost 40 million people living with HIV across the globe as of 2016 (UNAIDS, 2017). Although the new infection rate has reduced by almost $40 \%$, it remains a global health challenge with at least 35 million people still living with the virus in spite of this remarkable progress 
(Wilson et al., 2011; UNAIDS, 2014). Low- and middle-income countries continue to bear the largest burden of HIV cases and sub-Saharan Africa (SSA) accounts for almost two-thirds of people living with HIV (UNAIDS, 2017). The virus is a public health concern that needs to be tackled, and goal three of the Sustainable Development Goals (SDGs) seeks to end AIDS and other diseases including tuberculosis, malaria and neglected tropical diseases and combat hepatitis and water-borne diseases by 2030 (UNAIDS, 2018).

The virus has been destructive in SSA due to the existence of different strains of HIV, economic marginalization, poverty and sexually transmitted infections (STIs), coupled with opportunistic infections (Amuche et al., 2017). The main mode of transmission is by sexual intercourse, and it occurs across all categories of the population, including children, young people, adults, women and men. However, there are new occurrences of HIV infections among men in the general population as well as female sex workers, people who inject drugs and men who have sex with men (National AIDS Control Council, 2014; UNAIDS, 2015b).

The reduced rate of new infections in many SSA countries is as a result of behavioural changes such as increased condom use, fewer sexual partners and delayed sexual debut among young adults (Ghys et al., 2010). It is estimated that less than half of young adults worldwide have an error-free knowledge of HIV. Undoubtedly, there has been an improvement in knowledge and awareness of HIV transmission (Ghys et al., 2010; UNAIDS, 2010). The virus has impacted negatively on the economies in the world, especially in SSA (World Health Organization [WHO], 2015). Although HIV-related deaths in SSA have declined and new infection rates have stabilized, only $45 \%$ of people in SSA know their HIV status and men are more likely to be unaware of their status than women (UNAIDS, 2014).

In SSA, males are less likely to access health services compared with females, as evidence suggests various challenges to the uptake of HIV testing. Individual factors such as gender norms, fear of results, stigma and discrimination, low perception of risk and fear of disclosure, as well as provider attitude and confidentiality, inadequate supplies and equipment, have been documented to hinder access to testing services (Sylvester et al., 2010; Ziraba et al., 2011; Shattuck et al., 2013; Treves-Kagan et al., 2017; Rhead et al., 2019). People living with undiagnosed HIV, especially men, contribute significantly to the transmission of the virus (Hall et al., 2012).

There is still no effective vaccine for HIV. However, measures have been taken to scale up HIV preventive measures and voluntary counselling and testing (VCT) among men in SSA. Despite this, testing coverage remains low among men in many SSA countries (Kharsany \& Karim, 2016; Statistics South Africa, 2017). However, it has seen some improvement based on community and home-based HIV counselling and testing models (DiCarlo et al., 2014; Hensen et al., 2014, 2015). HIV testing, as an intervention in itself, underlies the effectiveness of most other prevention approaches (Sullivan et al., 2012).

Historically, there is only limited self-testing rates available for men with HIV, and SSA is no exception, with the proportion of the male population receiving an HIV test and obtaining a test result in the last 1 year spanning from $1.6 \%$ in Niger to $41.7 \%$ in Eritrea (Instituto Nacional de Saude et al., 2010). A focus on knowledge, prevention and treatment among men should greatly impact on mortality, new infections and the economic impact of HIV in SSA (Mills et al., 2012). Mozambique has been severely impacted by HIV/AIDS (Gona et al., 2020). It increased the number of adults undergoing HIV testing compared with baseline testing rate in 2003, but by 2009 only a minority of men (17.2\%) reported ever receiving an HIV test and being aware of their status (WHO et al., 2010). Mozambique is ranked amongst the highest in terms of HIV prevalence (Instituto Nacional de Saude et al., 2010). It is among the ten countries in the world with the highest HIV burden and accounts for $8 \%$ of all new HIV infections in SSA, with HIV prevalence of 13.2\% in adults aged 15-49 in 2009 (Mocumbi et al., 2017).

Kenya is recognized as a priority in SSA and is one of its hardest hit countries, with almost 2 million people living with the virus (Kimanga et al., 2014; Kharsany \& Karim, 2016; UNAIDS, 2017). Nonetheless, about $84 \%$ of infected persons in Kenya were unaware of their HIV status in 2013, resulting in a call for universal access to HIV testing (Ng'ang'a et al., 2014). HIV testing 
has been part of many national household surveys, including the Kenya Demographic and Health Surveys (2003 and 2008-09) and the Kenya AIDS Indicator Survey (KAIS) in 2007. These surveys estimated that HIV prevalence in adults ranged from 6.3\% to 7.4\% (Kimanga et al., 2014). The HIV incidence rate is currently $7 \%$, with a number of new infections occurring almost always in specific key populations, including female sex workers, men who have sex with men and people who inject drugs (Kharsany \& Karim, 2016; Bhattacharjee, 2019).

The UNAIDS $95-95-95$ by 2030 targets are for at least $95 \%$ of the world population being made aware of their HIV status and an 'AIDS-free generation' (UNAIDS, 2014). This meant HIV/AIDS prevention and treatment campaigns focusing on other sub-population group, including women and children (Mills et al., 2012). This means that fewer measures have directly targeted HIV prevention, testing and care at men in SSA (Mills et al., 2012; Gunn et al., 2016). While some studies on HIV among men in Kenya and Mozambique largely focused on their role in the Prevention of Mother to Child Transmission (PMTCT) services or oral self-testing, and less on men as HIV testing clients (Okal et al., 2020) and men who have sex with men (Horth et al., 2015), no previous study has assessed the comprehensive HIV/AIDS knowledge and testing of men in Kenya and Mozambique. The purpose of this study was therefore to assess the association between comprehensive HIV/AIDS knowledge and HIV testing among men in Kenya and Mozambique. It was hypothesized that there would be a positive association between comprehensive HIV/AIDS knowledge and the probability of being tested for HIV.

\section{Methods}

\section{Study design and data source}

The study utilized data from the men's re-code file of the Demographic and Health Surveys of Mozambique in 2015 and Kenya in 2014. The DHS is a nationally representative survey that is conducted in over 85 low- and middle-income countries globally. It focuses on essential markers such as breastfeeding, fertility, family planning, immunization, HIV/AIDS, child health and nutrition (Corsi et al., 2012). The survey employs a two-stage stratified sampling technique, which makes the data nationally representative. The study by Aliaga and Ruilin (2006) provides details of the sampling process. A total of 3395 men in Mozambique and 8433 men in Kenya who had complete information on all the variables of interest were included in the study. The Strengthening the Reporting of Observational Studies in Epidemiology' (STROBE) statement was followed closely when writing the manuscript (Von Elm et al., 2007). The dataset is freely available for download at: https://dhsprogram.com/data/available-datasets.cfm

\section{Definition of variables}

Outcome variable

The outcome variable was 'HIV/AIDS testing', derived from survey responses to the question 'Have you ever tested for HIV?' Responses were 'Yes' and 'No', and were coded as No=0 and Yes=1 (Seidu, 2020).

\section{Independent variables}

The main independent variable was 'comprehensive HIV/AIDS knowledge, defined as: i) knowing that consistent use of condoms during sexual intercourse and having just one uninfected faithful partner can reduce the chance of getting an HIV infection; ii) knowing that a healthy-looking person can have the AIDS virus; and iii) rejecting the two most common local misconceptions about AIDS transmission or prevention (i.e. it is transmitted via mosquito bites or witchcraft/ supernatural means). Comprehensive HIV knowledge was dichotomously coded Yes $=1$ if a respondent demonstrated correct knowledge of all the preceding elements and No $=0$ if a 
respondent did not demonstrate correct knowledge of all the elements (Ochako et al., 2011; Agegnehu et al., 2020; Darteh, 2020).

\section{Control variables}

Eleven control variables were considered, broadly grouped into individual and contextual variables. The individual variables included age, employment status, marital status, educational level, frequency of reading newspapers/magazines, frequency of listening to radio, frequency of watching television, condom use and number of sexual partners. The contextual factors included wealth quintile and urban/rural place of residence. These variables were not determined a priori, but were based on parsimony, theoretical relevance and practical significance with HIV/AIDS testing.

\section{Statistical analyses}

The data were analysed with Stata version 14.0. The analysis was done in three steps. The first step was the computation of the prevalence of HIV testing in Mozambique and Kenya. The second step was a bivariate analysis that calculated the proportions of HIV/AIDS testing across the outcome variable with their significance levels (Table 1). The last step of the analysis was a binary logistic analysis, using the variables that were significant from the chi-squared test of fitness, which was carried out in a hierarchical order. Three models were used for the logistic regression analysis. The first model, Model I, looked at the bivariate analysis of comprehensive knowledge of HIV/AIDS and HIV/AIDS testing in Mozambique and Kenya. In Model II, individual variables were added to Model I. Finally, individual and contextual variables were added to form the complete model.

\section{Results}

\section{HIV testing by explanatory variables in Mozambique}

Table 1 shows HIV testing by explanatory variables in Mozambique. The overall prevalence of HIV testing among men in Mozambique was 46.7\%. Apart from number of sexual partners, all the explanatory variables showed significant associations with HIV testing among men in Mozambique. More than half (55.3\%) of the men who had comprehensive knowledge of HIV/ AIDS tested for their HIV status. In Mozambique, the age groups of men with the largest proportions testing for HIV were 25-29 years (57.0\%), 30-39 years (52.1\%) and 55-59 years (51.8\%). Less than half $(49.1 \%)$ of men who were working had tested for HIV. A greater proportion of men who were cohabiting (57.3\%) had tested for HIV than those of other marital statuses. The richest (67.9\%), those with secondary/higher education (63.8\%), those who read newspapers/magazines at least once a week (69.7\%), those who listened to radio at least once a week (53.2\%), those who watched television (64.6\%), those who used a condom during sex (62.8\%) and those residing in urban centres (59.0\%) were the groups reporting the highest proportions of HIV testing. Also, less than half $(49.3 \%)$ of the men with multiple sexual partners had tested for HIV.

\section{HIV testing by explanatory variables in Kenya}

Table 2 shows HIV testing by explanatory variables in Kenya. The overall prevalence of HIV testing in Kenya was $80.1 \%$. All the explanatory variables had significant associations with HIV testing among men in Kenya. A large majority of the men who had comprehensive knowledge of HIV/AIDS (81.8\%) had tested for HIV. In Kenya, the age groups of men with the largest proportions testing for HIV were 15-19 years (56.4\%), 20-24 years (81.9\%), 25-29 years $(85.4 \%), 30-34$ years (83.5\%), 35-39 years (80.4\%), 40-44 years (81.6\%), 45-49 years (77.6\%) and 50-55 years (75.5\%). A greater proportion of men who were working $(80.9 \%)$ and who were married (82.6\%) tested for HIV than those who were not working or who were unmarried. The richest $(86.3 \%)$, 
Table 1. HIV testing by explanatory variables in Mozambique

\begin{tabular}{|c|c|c|c|c|}
\hline Variable & Weighted $n$ & Weighted \% & Received HIV test & $p$-value \\
\hline \multicolumn{4}{|c|}{ Comprehensive knowledge about HIV/AIDS } & $<0.001$ \\
\hline No & 1957 & 57.6 & 40.4 & \\
\hline Yes & 1438 & 42.4 & 55.3 & \\
\hline \multicolumn{4}{|l|}{ Age } & $<0.001$ \\
\hline $15-19$ & 413 & 12.2 & 26.4 & \\
\hline $20-24$ & 650 & 19.1 & 45.9 & \\
\hline $25-29$ & 507 & 14.9 & 57.0 & \\
\hline $30-34$ & 463 & 13.6 & 52.1 & \\
\hline $35-39$ & 381 & 11.2 & 52.1 & \\
\hline $40-44$ & 324 & 9.5 & 49.0 & \\
\hline $45-49$ & 283 & 8.3 & 41.5 & \\
\hline $50-54$ & 212 & 6.3 & 42.4 & \\
\hline $55-59$ & 162 & 4.8 & 51.8 & \\
\hline \multicolumn{4}{|l|}{ Employment status } & $<0.001$ \\
\hline Not working & 582 & 17.1 & 35.1 & \\
\hline Working & 2813 & 82.9 & 49.1 & \\
\hline \multicolumn{4}{|l|}{ Marital status } & $<0.001$ \\
\hline Not married & 785 & 23.1 & 43.8 & \\
\hline Married & 1206 & 35.5 & 37.0 & \\
\hline Cohabiting & 1213 & 35.7 & 57.3 & \\
\hline Other & 190 & 5.6 & 52.5 & \\
\hline \multicolumn{4}{|l|}{ Educational level } & $<0.001$ \\
\hline No education & 322 & 9.5 & 26.4 & \\
\hline Primary & 1740 & 51.3 & 37.4 & \\
\hline Secondary/Higher & 1333 & 39.2 & 63.8 & \\
\hline \multicolumn{4}{|c|}{ Frequency of reading newspapers/magazines } & $<0.001$ \\
\hline Not at all & 2258 & 66.5 & 37.6 & \\
\hline Less than once a week & 639 & 18.8 & 60.9 & \\
\hline At least once a week & 498 & 14.7 & 69.7 & \\
\hline \multicolumn{4}{|c|}{ Frequency of listening to radio } & $<0.001$ \\
\hline Not at all & 1056 & 31.1 & 34.7 & \\
\hline Less than once a week & 716 & 21.1 & 49.8 & \\
\hline At least once a week & 1623 & 47.8 & 53.2 & \\
\hline \multicolumn{4}{|c|}{ Frequency of watching television } & $<0.001$ \\
\hline Not at all & 1856 & 54.7 & 33.7 & \\
\hline Less than once a week & 305 & 9.0 & 53.6 & \\
\hline At least once a week & 1234 & 36.3 & 64.6 & \\
\hline
\end{tabular}


Table 1. (Continued)

\begin{tabular}{|c|c|c|c|c|}
\hline Variable & Weighted $n$ & Weighted \% & Received HIV test & $p$-value \\
\hline Condom used during last sex & & & & $<0.001$ \\
\hline No & 2698 & 79.5 & 42.6 & \\
\hline Yes & 697 & 20.5 & 62.8 & \\
\hline Number of sexual partners & & & & 0.194 \\
\hline One & 1978 & 58.3 & 44.8 & \\
\hline Many & 1417 & 41.7 & 49.3 & \\
\hline Wealth index & & & & $<0.001$ \\
\hline Poorest & 527 & 15.5 & 24.3 & \\
\hline Poorer & 606 & 17.8 & 39.9 & \\
\hline Middle & 583 & 17.2 & 41.3 & \\
\hline Richer & 673 & 19.8 & 52.4 & \\
\hline Richest & 1007 & 29.7 & 67.9 & \\
\hline Place of residence & & & & $<0.001$ \\
\hline Urban & 1435 & 42.3 & 59.0 & \\
\hline Rural & 1960 & 57.7 & 37.7 & \\
\hline Total & 3395 & 100.0 & 46.7 & \\
\hline
\end{tabular}

those with secondary/higher education (85.4\%), those who were exposed to newspapers at least once a week (85.7\%), those who were exposed to radio at least once a week $(81.3 \%)$, those who were exposed to television (83.8\%), those who used a condom during sex (82.2\%) and those residing in urban centres $(84.4 \%)$ were the groups reporting the highest proportions of HIV testing. Also, a greater proportion $(82.0 \%)$ of the men with one sexual partner tested for HIV than those with many sexual partners.

\section{Binary logistic regression of the association between comprehensive HIV/AIDs knowledge and HIV testing}

Table 3 shows the binary logistic regression of the association between comprehensive HIV/AIDS knowledge and HIV testing among men in Mozambique and Kenya. Men in Mozambique who had comprehensive HIV/AIDS knowledge $(\mathrm{aOR}=1.26$, CI: $1.07-1.47)$ were more likely to test for HIV compared with their counterparts who had no comprehensive HIV/AIDS knowledge. Similarly, in Kenya, those who had comprehensive HIV/AIDS knowledge (AOR=1.23, CI: 1.09-1.39) were also more likely to test for HIV compared with their counterparts who had no comprehensive HIV/AIDS knowledge.

\section{Discussion}

This study examined the association between comprehensive HIV/AIDS knowledge and HIV testing among men in Kenya and Mozambique. The prevalence of HIV testing among men was higher in Kenya (80.1\%) than in Mozambique (46.7\%). Staveteig et al. (2013) reported similar but lower HIV testing prevalences for men in Kenya (40.4\%) and Mozambique (17.2\%). Other previous studies in Kenya (Cherutich et al., 2012; Waruiru et al., 2014) and Mozambique (De Schacht 
Table 2. HIV testing by explanatory variables in Kenya

\begin{tabular}{|c|c|c|c|c|}
\hline Variable & Weighted $n$ & Weighted \% & Received HIV test & $p$-value \\
\hline \multicolumn{4}{|c|}{ Comprehensive knowledge about HIV/AIDS } & $<0.001$ \\
\hline No & 2146 & 25.5 & 75.1 & \\
\hline Yes & 6287 & 74.5 & 81.8 & \\
\hline Age & & & & $<0.001$ \\
\hline $15-19$ & 568 & 6.7 & 56.4 & \\
\hline $20-24$ & 1358 & 16.1 & 81.9 & \\
\hline $25-29$ & 1626 & 19.3 & 85.4 & \\
\hline $30-34$ & 1456 & 17.3 & 83.5 & \\
\hline $35-39$ & 1205 & 14.3 & 80.4 & \\
\hline $40-44$ & 1006 & 11.9 & 81.6 & \\
\hline $45-49$ & 623 & 7.4 & 77.6 & \\
\hline $50-54$ & 590 & 7.0 & 75.5 & $<0.001$ \\
\hline \multicolumn{5}{|l|}{ Employment status } \\
\hline Not working & 503 & 6.0 & 67.4 & \\
\hline Working & 7930 & 94.0 & 80.9 & \\
\hline Marital status & & & & $<0.001$ \\
\hline Not married & 2248 & 26.6 & 74.3 & \\
\hline Married & 5505 & 65.3 & 82.6 & \\
\hline Cohabiting & 236 & 2.8 & 81.1 & \\
\hline Other & 443 & 5.3 & 77.8 & \\
\hline Educational level & & & & $<0.001$ \\
\hline No education & 188 & 2.2 & 48.0 & \\
\hline Primary & 3945 & 46.8 & 75.9 & \\
\hline Secondary/Higher & 4300 & 51.0 & 85.4 & \\
\hline \multicolumn{4}{|c|}{ Frequency of reading newspapers/magazines } & $<0.001$ \\
\hline Not at all & 2826 & 33.5 & 72.1 & \\
\hline Less than once a week & 1818 & 21.6 & 80.8 & \\
\hline At least once a week & 3789 & 44.9 & 85.7 & \\
\hline \multicolumn{4}{|c|}{ Frequency of listening to radio } & $<0.001$ \\
\hline Not at all & 361 & 4.3 & 68.7 & \\
\hline Less than once a week & 618 & 7.3 & 72.2 & \\
\hline At least once a week & 7454 & 88.4 & 81.3 & \\
\hline \multicolumn{4}{|c|}{ Frequency of watching television } & $<0.001$ \\
\hline Not at all & 1678 & 19.9 & 70.0 & \\
\hline Less than once a week & 1417 & 16.8 & 78.3 & \\
\hline At least once a week & 5338 & 63.3 & 83.8 & \\
\hline
\end{tabular}


Table 2. (Continued)

\begin{tabular}{|c|c|c|c|c|}
\hline Variable & Weighted $n$ & Weighted \% & Received HIV test & $p$-value \\
\hline Condom used during last sex & & & & $<0.001$ \\
\hline No & 6002 & 71.2 & 79.3 & \\
\hline Yes & 2431 & 28.8 & 82.2 & \\
\hline Number of sexual partners & & & & $<0.001$ \\
\hline One & 5171 & 61.3 & 82.0 & \\
\hline Many & 3262 & 38.7 & 77.1 & \\
\hline Wealth index & & & & $<0.001$ \\
\hline Poorest & 960 & 11.4 & 69.0 & \\
\hline Poorer & 1429 & 17.0 & 76.7 & \\
\hline Middle & 1604 & 19.0 & 77.8 & \\
\hline Richer & 2160 & 25.6 & 82.5 & \\
\hline Richest & 2279 & 27.0 & 86.3 & \\
\hline Place of residence & & & & $<0.001$ \\
\hline Urban & 3990 & 47.3 & 84.4 & \\
\hline Rural & 4443 & 52.7 & 76.3 & \\
\hline Total & 8433 & 100.0 & 80.1 & \\
\hline
\end{tabular}

et al., 2014; Horth et al., 2015) also reported a lower prevalence of HIV testing among men than the present study. The variations in the prevalence figures could be attributed to the different periods in which the studies were conducted. Perhaps the high prevalence of HIV testing among men in the two countries recorded in the present study could be attributed to HIV testing intervention programmes implemented in these countries in the past few years.

In Mozambique, for instance, increased funding from foreign governments and international organizations has resulted in a significant increase in the number of health care units providing voluntary counselling and testing services (Yao et al., 2014). Apart from the improved access to, and minimization of, structural barriers to HIV testing (Yao et al., 2014; Ha et al., 2019), the use of community-based advocacy and intervention programmes such as 'Male Champions' and male-tomale community health agents to counsel male partners on the importance HIV testing has also contributed to an increased HIV testing uptake among men in Mozambique (Audet et al., 2016).

With regards to Kenya, increased HIV testing rates among men had been associated with interventions such as male involvement in Prevention of Mother-To-Child HIV Transmission (PMTCT) services (Osoti et al., 2014), as well as the use of home-based voluntary counselling and testing services (Aluisio et al., 2011; Waruiru et al., 2014). Kenya and Mozambique are also beneficiaries of the US President's Emergency Plan for AIDS Relief (PEPFAR), which has contributed immensely towards the management and prevention of HIV/AIDS, including scalingup of HIV testing programmes in the two countries (El-Sadr et al., 2012; Fauci \& Eisinger, 2018).

Despite the relatively high rate of HIV testing uptake among men in Kenya and Mozambique, Kenya recorded a higher testing rate $(80.1 \%)$ than Mozambique $(53.3 \%)$. The high level of stigma towards people living with HIV/AIDS in Mozambique (20.7\%) than Kenya (11.9\%) (UNAIDS, 2017) might have contributed to the lower testing rate among men in Mozambique. Recent studies have shown that stigma continues to be one of the major barriers to HIV testing uptake among men in Mozambique (Ha et al., 2019) and elsewhere in SSA (Hatzold et al., 2019; Hlongwa et al., 2020; Sullivan et al., 2020). Meanwhile, high HIV testing uptake among men is important for the 
Table 3. Binary logistic regression on the association between comprehensive HIV/AIDS knowledge and HIV testing among men in Mozambique and Kenya

\begin{tabular}{|c|c|c|c|}
\hline \multirow[b]{2}{*}{ Variable } & Mozambique & \multicolumn{2}{|c|}{ Kenya } \\
\hline & $\begin{array}{c}\text { Model II } \\
\text { aOR }(95 \% \mathrm{CI})\end{array}$ & $\begin{array}{c}\text { Model I } \\
\text { cOR }(95 \% \mathrm{Cl})\end{array}$ & $\begin{array}{c}\text { Model II } \\
\text { aOR }(95 \% \mathrm{CI})\end{array}$ \\
\hline \multicolumn{4}{|l|}{ Comprehensive knowledge about HIV/AIDS } \\
\hline \multicolumn{4}{|l|}{ No (Ref.) } \\
\hline $1.92^{\star \star \star}(1.67-2.20)$ & $1.26^{\star \star}(1.07-1.47)$ & $1.56^{\star \star \star}(1.40-1.75)$ & $1.23^{\star \star \star}(1.09-1.39)$ \\
\hline \multicolumn{4}{|l|}{ Age } \\
\hline \multicolumn{4}{|l|}{ 15-19 (Ref.) } \\
\hline $20-24$ & $2.12^{\star \star \star}(1.58-2.83)$ & & $2.52^{\star \star \star}(2.00-3.17)$ \\
\hline $25-29$ & $3.16^{\star \star \star}(2.24-4.47)$ & & $2.80^{\star \star \star}(2.16-3.62)$ \\
\hline $30-34$ & $3.17^{\star \star \star}(2.18-4.60)$ & & $2.33^{\star \star \star}(1.67-2.96)$ \\
\hline $35-39$ & $3.73^{\star \star \star}(2.52-5.53)$ & & $2.22^{\star \star \star}(1.67-2.96)$ \\
\hline $40-44$ & $3.77^{\star \star \star}(2.53-5.61)$ & & $1.91^{\star \star \star}(1.43-2.57)$ \\
\hline $45-49$ & $2.62^{\star \star \star}(1.74-3.93)$ & & $1.55^{\star \star}(1.14-2.10)$ \\
\hline $50-54$ & $2.28^{\star \star *}(1.49-3.49)$ & & $1.34(0.98-1.82)$ \\
\hline $55-59$ & $3.66^{\star \star \star}(2.33-5.74)$ & & - \\
\hline \multicolumn{4}{|l|}{ Employment status } \\
\hline \multicolumn{4}{|l|}{ Not working (Ref.) } \\
\hline Working & $1.23(0.98-1.55)$ & & $1.17(0.93-1.47)$ \\
\hline \multicolumn{4}{|l|}{ Marital status } \\
\hline \multicolumn{4}{|l|}{ Not married (Ref.) } \\
\hline Married & $1.44^{\star}(1.06-1.94)$ & & $2.53^{\star \star \star}(1.92-3.33)$ \\
\hline Cohabiting & $2.25^{\star \star \star}(1.68-3.00)$ & & $2.94^{\star \star \star}(1.90-4.55)$ \\
\hline Other & $1.44(0.97-2.14)$ & & $1.40^{\star}(1.05-1.86)$ \\
\hline \multicolumn{4}{|l|}{ Educational level } \\
\hline \multicolumn{4}{|l|}{ No education (Ref.) } \\
\hline Primary & $1.45^{\star}(1.07-1.96)$ & & $2.09^{\star \star \star}(1.64-2.67)$ \\
\hline Secondary/Higher & $2.69^{\star \star \star}(1.92-3.75)$ & & $3.03^{\star \star \star}(2.32-3.97)$ \\
\hline \multicolumn{4}{|l|}{ Frequency of reading newspapers/magazines } \\
\hline \multicolumn{4}{|l|}{ Not at all (Ref.) } \\
\hline Less than once a week & $1.40^{\star \star \star}(1.13-1.74)$ & & $1.12(0.96-1.31)$ \\
\hline At least once a week & $2.02^{\star \star \star}(1.57-2.59)$ & & $1.42^{\star \star \star}(1.22-1.65)$ \\
\hline \multicolumn{4}{|l|}{ Frequency of listening to radio } \\
\hline \multicolumn{4}{|l|}{ Not at all (Ref.) } \\
\hline Less than once a week & $1.20(0.95-1.51)$ & & $0.95(0.72-1.24)$ \\
\hline At least once a week & $1.08(0.89-1.32)$ & & $1.17(0.93-1.47)$ \\
\hline
\end{tabular}

(Continued) 
Table 3. (Continued)

\begin{tabular}{|c|c|c|c|c|}
\hline \multirow[b]{2}{*}{ Variable } & \multicolumn{2}{|c|}{ Mozambique } & \multicolumn{2}{|c|}{ Kenya } \\
\hline & $\begin{array}{c}\text { Model I } \\
\text { cOR }(95 \% \mathrm{Cl})\end{array}$ & $\begin{array}{c}\text { Model II } \\
\text { aOR }(95 \% \mathrm{Cl})\end{array}$ & $\begin{array}{c}\text { Model I } \\
\text { cOR }(95 \% \mathrm{Cl})\end{array}$ & $\begin{array}{c}\text { Model II } \\
\text { aOR (95\% Cl) }\end{array}$ \\
\hline \multicolumn{5}{|c|}{ Frequency of watching television } \\
\hline \multicolumn{5}{|l|}{ Not at all (Ref.) } \\
\hline \multicolumn{2}{|l|}{ Less than once a week } & $1.12(0.82-1.53)$ & & $1.31^{\star \star}(1.11-1.55)$ \\
\hline \multicolumn{2}{|l|}{ At least once a week } & $1.34^{\star}(1.02-1.77)$ & & $1.22^{\star \star}(1.05-1.43)$ \\
\hline \multicolumn{5}{|c|}{ Condom used during last sex } \\
\hline \multicolumn{5}{|l|}{ No (Ref.) } \\
\hline \multicolumn{2}{|l|}{ Yes } & $1.69^{\star \star \star}(1.36-2.10)$ & & $2.12^{\star \star \star}(1.81-2.49)$ \\
\hline \multicolumn{5}{|l|}{ Number of sexual partners } \\
\hline \multicolumn{2}{|l|}{ One } & - & & \\
\hline \multicolumn{2}{|l|}{ Many } & - & & $1.11(0.90-1.38)$ \\
\hline \multicolumn{5}{|l|}{ Wealth index } \\
\hline \multicolumn{5}{|l|}{ Poorest (Ref.) } \\
\hline \multicolumn{2}{|l|}{ Poorer } & $1.25(0.90-1.74)$ & & $1.21^{*}(1.02-1.45)$ \\
\hline \multicolumn{2}{|l|}{ Middle } & $1.74^{\star \star \star}(1.26-2.39)$ & & $1.14(0.95-1.36)$ \\
\hline \multicolumn{2}{|l|}{ Richer } & $2.54^{\star \star \star}(1.80-3.58)$ & & $1.20(0.99-1.45)$ \\
\hline \multicolumn{2}{|l|}{ Richest } & $3.74^{\star \star \star}(2.50-5.61)$ & & $1.26(1.00-1.59)$ \\
\hline \multicolumn{5}{|l|}{ Place of residence } \\
\hline \multicolumn{5}{|l|}{ Urban (Ref.) } \\
\hline \multicolumn{2}{|l|}{ Rural } & $1.50^{\star \star}(1.18-1.91)$ & & $0.92(0.81-1.05)$ \\
\hline$N$ & 3395 & 3395 & 8433 & 8433 \\
\hline Pseudo $R^{2}$ & 0.019 & 0.162 & 0.007 & 0.081 \\
\hline
\end{tabular}

${ }^{\star} p<0.05 ;{ }^{* \star} p<0.01 ;{ }^{* \star *} p<0.001$.

Ref. $=$ reference category.

early initiation of treatment and to reduce the morbidity and mortality associated with the disease (Hatzold et al., 2019). This calls for interventions to scale up HIV testing among men, especially in Mozambique where only $61 \%$ of men who have HIV know their status, compared with $88 \%$ in Kenya (UNAIDS, 2019).

In this study, comprehensive HIV/AIDS knowledge was found to be associated with a higher prevalence and odds of HIV testing among men in both Kenya and Mozambique. Specifically, men who had comprehensive HIV/AIDS knowledge in Kenya (81.8\%) and Mozambique (55.3\%) had higher odds of testing for HIV compared with their counterparts who had no comprehensive HIV/AIDS knowledge. This finding was significant, even after controlling for age, employment status, marital status, educational level, condom use, wealth quintile, type of residence and exposure to newspapers, radio or television. The findings support those of previous studies conducted in Uganda (Gage \& Ali, 2005), Burkina Faso (De Allegri et al., 2015) and Ghana (Nyarko \& Sparks, 2020). One possible reason for this finding is that men with comprehensive HIV/AIDS knowledge are more likely to have higher education and increased access to 
information from the media, as found in the present study and in previous studies in SSA (Asaolu et al., 2016; Fleming et al., 2019). Men with comprehensive HIV/AIDS knowledge are better informed about the importance of HIV testing and where to access an HIV test, which may increase their likelihood of getting tested (Bwambale et al., 2008; Onsomu et al., 2013; Fleming et al., 2019). Conversely, low educational attainment and limited access to information on HIV/AIDS has been shown to be related to low levels of HIV/AIDS knowledge and its associated misinformation, misconceptions and stigma (Bwambale et al., 2008; Sharma et al., 2015; Mumtaz et al., 2020), which are among the major barriers to HIV test uptake among men in Kenya and Mozambique (Fleming et al., 2019). Thus, improving HIV/AIDS knowledge through the dissemination of information in communities could reduce the misconceptions, misinformation and stigma associated with the disease (Stephenson et al., 2013). This could further improve testing rate among men in both countries.

This study's major strength was the use of nationally representative data. However, it had its limitations. First, data were limited to 2015 and 2014 DHS data, so HIV testing prevalence figures were limited to the periods for which these DHS data were collected. For example, new developments in the area of HIV testing such as the large-scale introduction of oral self-test HIV kits in Kenya in the year 2017 (UNAIDS, 2017) might have significantly changed the prevalence of HIV testing in the country. Secondly, the cross-sectional nature of the study did not allow for causality to be inferred from the findings. Additionally, HIV test self-reporting is subject to recall bias, which can result in under- or over-reporting. Finally, some factors related to culture and religion were not included in the analysis due to the absence of complete data on these variables in the datasets.

In conclusion, this study found a significant association between comprehensive HIV/AIDS knowledge and HIV testing among men in Kenya and Mozambique. Therefore, to improve the HIV testing rate among men in these countries, it is important that interventions are geared towards improvement in comprehensive HIV/AIDS knowledge, especially among men. This would ensure the realization of the global HIV/AIDS target of 95-95-95 by the year 2030 (Ajayi et al., 2020). Also, ensuring that all men have access to comprehensive HIV/AIDS education could reduce the stigma and misinformation associated with the disease, thereby further improving HIV testing uptake.

Funding. This research received no specific grant from any funding agency, commercial entity or not-for-profit organization.

Conflicts of Interest. The authors have no conflict of interest to declare.

Ethical Approval. The DHS reports that ethical clearances were obtained from the Ethics Committee of ORC Macro Inc., as well as from the ethics boards of partner organizations in Mozambique and Kenya, including the Ministries of Health. The DHS follows the standards for ensuring the protection of respondents' privacy. ICF International ensures that the survey complies with the United States Department of Health and Human Services' regulations for the respect of human subjects. This was a secondary analysis of data and therefore no further approval was required since the data are available in the public domain. Further information about the DHS data usage and ethical standards are available at http://goo.gl/ny8T6X.

\section{References}

Agegnehu CD, Geremew BM, Sisay MM, Muchie KF, Engida ZT, Gudayu TW and Liyew AM (2020) Determinants of comprehensive knowledge of HIV/AIDS among reproductive age (15-49 years) women in Ethiopia: further analysis of 2016 Ethiopian Demographic and Health Survey. AIDS Research and Therapy 17(1), 1-9.

Ajayi AI, Awopegba OE, Adeagbo OA and Ushie BA (2020) Low coverage of HIV testing among adolescents and young adults in Nigeria: implication for achieving the UNAIDS first 95. PloS One 15(5), e0233368.

Aliaga A and Ruilin R (2006) Cluster optimal sample size for Demographic and Health Surveys. In the 7th International Conference on Teaching Statistics - ICOTS, pp. 2-7.

Aluisio A, Richardson BA, Bosire R, John-Stewart G, Mbori-Ngacha D and Farquhar C (2011). Male antenatal attendance and HIV testing are associated with decreased infant HIV infection and increased HIV free survival. Journal of Acquired Immune Deficiency Syndromes 56(1), 76. 
Amuche NJ, Emmanuel EI and Innocent NE (2017) HIV/AIDS in sub-Saharan Africa: current status, challenges and prospects. Asian Pacific Journal of Tropical Diseases 7(4), 239-256.

Asaolu IO, Gunn JK, Center KE, Koss MP, Iwelunmor JI and Ehiri JE (2016) Predictors of HIV testing among youth in subSaharan Africa: a cross-sectional study. PloS One 11(10), e0164052.

Audet CM, Blevins M, Chire YM, Aliyu MH, Vaz LM, Antonio E and Vermund SH (2016) Engagement of men in antenatal care services: increased HIV testing and treatment uptake in a community participatory action program in Mozambique. AIDS and Behavior 20(9), 2090-2100.

Bhattacharjee P, Rego D, Musyoki H, Becker M, Pickles M, Isac S et al. (2019) Evaluation of community-based HIV selftesting delivery strategies on reducing undiagnosed HIV infection, and improving linkage to prevention and treatment services, among men who have sex with men in Kenya: a programme science study protocol. BMC Public Health $19,986$.

Bwambale FM, Ssali SN, Byaruhanga S, Kalyango JN and Karamagi CA (2008) Voluntary HIV counselling and testing among men in rural western Uganda: implications for HIV prevention. BMC Public Health 8(1), 1-12.

Cherutich P, Kaiser R, Galbraith J, Williamson J, Shiraishi RW, Ngare C and KAIS Study Group (2012) Lack of knowledge of HIV status a major barrier to HIV prevention, care and treatment efforts in Kenya: results from a nationally representative study. PloS One 7(5), e36797.

Corsi DJ, Neuman M, Finlay JE and Subramanian SV (2012) Demographic and Health Surveys: a profile. International Journal of Epidemiology 41(6), 1602-1613.

Darteh EK (2020) Individual and contextual predictors of comprehensive HIV and AIDS knowledge among young females in Ghana. African Journal of AIDS Research 19(3), 222-230.

De Allegri M, Agier I, Tiendrebeogo J, Louis VR, Yé M, Mueller O and Sarker M (2015) Factors affecting the uptake of HIV testing among men: a mixed-methods study in rural Burkina Faso. PLoS One 10(7), e0130216.

De Schacht C, Hoffman HJ, Mabunda N, Lucas C, Alons CL, Madonela A and Guay L (2014) High rates of HIV seroconversion in pregnant women and low reported levels of HIV testing among male partners in Southern Mozambique: results from a mixed methods study. PloS One 9(12), e115014.

DiCarlo AL, Mantell JE, Remien RH, Zerbe A, Morris D, Pitt B et al. (2014) 'Men usually say that HIV testing is for women': gender dynamics and perceptions of HIV testing in Lesotho. Culture Health Sexuality 16(8), 867-882.

El-Sadr WM, Holmes CB, Mugyenyi P, Thirumurthy H, Ellerbrock T, Ferris R et al. (2012) Scale-up of HIV treatment through PEPFAR: a historic public health achievement. Journal of Acquired Immune Deficiency Syndromes $\mathbf{6 0}$ (Supplement 3), S96-S104.

Fauci AS and Eisinger RW (2018) PEPFAR - 15 years and counting the lives saved. New England Journal of Medicine 378(4), 314-316.

Fleming PJ, Rosen JG, Wong VJ and Carrasco MA (2019) Shedding light on a HIV blind spot: factors associated with men's HIV testing in five African countries. Global Public Health 14(9), 1241-1251.

Gage AJ and Ali D (2005) Factors associated with self-reported HIV testing among men in Uganda. AIDS Care 17(2), 153165.

Ghys PD, Gouws E, Lyerla R, Garcia-Calleja JM, Barrerre B et al. (2010) Trends in HIV prevalence and sexual behaviour among young people aged 15-24 years in countries most affected by HIV. Sexually Transmitted Infections 86(2), ii72-ii83.

Gona PN, Gona CM, Ballout S, Rao SR, Kimokoti R, Mapoma CC and Mokdad AH (2020) Burden and changes in HIV/ AIDS morbidity and mortality in Southern Africa Development Community Countries, 1990-2017. BMC Public Health 20 , $1-14$.

Gunn JK, Asaolu IO, Center KE, Gibson SJ, Wightman P, Ezeanolue EE and Ehiri JE (2016) Antenatal care and uptake of HIV testing among pregnant women in sub-Saharan Africa: a cross-sectional study. Journal of the International AIDS Society 19, 20605.

Ha JH, Van Lith LM, Mallalieu EC, Chidassicua J, Pinho MD, Devos P and Wirtz AL (2019) Gendered relationship between HIV stigma and HIV testing among men and women in Mozambique: a cross-sectional study to inform a stigma reduction and male-targeted HIV testing intervention. BMJ Open 9(10), e029748.

Hall HI, Holtgrave DR and Maulsby C (2012) HIV transmission rates from persons living with HIV who are aware and unaware of their infection. AIDS 26(7), 893-896.

Hatzold K, Gudukeya S, Mutseta MN, Chilongosi R, Nalubamba M, Nkhoma C and Corbett EL (2019) HIV self-testing: breaking the barriers to uptake of testing among men and adolescents in sub-Saharan Africa, experiences from STAR demonstration projects in Malawi, Zambia and Zimbabwe. Journal of the International AIDS Society 22, e25244.

Hensen B, Lewis JJ, Schaap A, Tembo M, Mutale W, Weiss HA, Hargreaves J and Ayles H (2015) Factors associated with HIV-testing and acceptance of an offer of home-based testing by men in rural Zambia. AIDS and Behavior 19(3), 492-504.

Hensen B, Taoka S, Lewis JJ, Weiss HA and Hargreaves JJA (2014) Systematic review of strategies to increase men's HIVtesting in sub-Saharan Africa. AIDS 28(14), 2133.

Hlongwa M, Mashamba-Thompson T, Makhunga S and Hlongwana K (2020) Barriers to HIV testing uptake among men in sub-Saharan Africa: a scoping review. African Journal of AIDS Research 19(1), 13-23. 
Horth RZ, Cummings B, Young PW, Mirjahangir J, Sathane I, Nala R et al. (2015) Correlates of HIV testing among men who have sex with men in three urban areas of Mozambique: missed opportunities for prevention. AIDS and Behavior 19(11), 1978-1989.

Instituto Nacional de Saúde, Instituto Nacional de Estatística and ICF Macro (2010) Inquérito Nacional de Prevalência, Riscos Comportamentais e Informação sobre o HIV e SIDA em Moçambique 2009. Calverton, MD, USA.

Kharsany AB and Karim QA (2016) HIV infection and AIDS in sub-Saharan Africa: current status, challenges and opportunities. Open AIDS Journal 10, 34-48.

Kimanga DO, Ogola S, Umuro M, Ng'ang'a A, Kimondo L, Murithi P et al. (2014) Prevalence and incidence of HIV infection, trends, and risk factors among persons aged 15-64 years in Kenya: results from a nationally representative study. Journal of Acquired Immune Deficiency Syndromes 66(1), S13-S26.

Mills EJ, Beyrer C, Birungi J and Dybul MR (2012) Engaging men in prevention and care for HIV/AIDS in Africa. PLoS Medicine 9(2), e1001167.

Mocumbi S, Gafos M, Munguambe K, Goodall R, McCormack S and Microbicides Development Programme (2017) High HIV prevalence and incidence among women in Southern Mozambique: evidence from the MDP microbicide feasibility study. PLoS One 12(3), e0173243.

Mumtaz GR, Hilmi N, Majed E Z and Abu-Raddad LJ (2020) Characterising HIV/AIDS knowledge and attitudes in the Middle East and North Africa: systematic review and data synthesis. Global Public Health 15(2), 275-298.

National AIDS Control Council (2014) Kenya AIDS Strategic Framework 2014/2015-2018/2019. Ministry of Health, Nairobi, Kenya.

Ng'ang'a A, Waruiru W, Ngare C, Ssempijja V, Gachuki T, Njoroge I et al. (2014) The status of HIV testing and counseling in Kenya: results from a nationally representative population-based survey. Journal of Acquired Immune Deficiency Syndromes, 66 (Supplement 1), S27-S36.

Nyarko SH and Sparks C (2020) Levels and determinants of HIV testing uptake among Ghanaian men. African Journal of AIDS Research 19(1), 40-47.

Ochako R, Ulwodi D, Njagi P, Kimetu S and Onyango A (2011) Trends and determinants of comprehensive HIV and AIDS knowledge among urban young women in Kenya. AIDS Research and Therapy 8(1), 1-8.

Okal J, Lango D, Matheka J, Obare F, Ngunu-Gituathi C, Mugambi M and Sarna A (2020) 'It is always better for a man to know his HIV status' - A qualitative study exploring the context, barriers and facilitators of HIV testing among men in Nairobi, Kenya. PloS One 15(4), e0231645.

Onsomu EO, Moore D, Abuya BA, Valentine P and Duren-Winfield V (2013) Importance of the media in scaling-up HIV testing in Kenya. SAGE Open 3(3), 2158244013497721.

Osoti AO, John-Stewart G, Kiarie J, Richardson B, Kinuthia J, Krakowiak D and Farquhar C (2014) Home visits during pregnancy enhance male partner HIV counseling and testing in Kenya: a randomized clinical trial. AIDS 28(1), 95.

Rhead R, Skovdal M, Takaruza A, Maswera R, Nyamukapa C and Gregson S (2019) The multidimensionality of masculine norms in east Zimbabwe: implications for HIV prevention, testing and treatment. AIDS 33(3), 537-46.

Seidu AA (2020) Using Anderson's model of health service utilization to assess the use of HIV testing services by sexually active men in Ghana. Frontiers in Public Health 8, 512.

Sharma M, Ying R, Tarr G and Barnabas R (2015) A systematic review and meta-analysis of community and facility-based approaches to address gaps in HIV testing and linkage in sub-Saharan Africa. Nature 528(7580), S77.

Shattuck D, Burke H, Ramirez C, Succop S, Costenbader B, Attafuah JD et al. (2013) Using the inequitable gender norms scale and associated HIV risk behaviors among men at high risk for HIV in Ghana and Tanzania. Men and Masculinities 16(5), 540-559.

Statistics South Africa (2017) South Africa Demographic and Health Survey 2016: Key Indicator Report. StatsSA, Pretoria. URL: https://www.statssa.gov.za/publications/Report\%2003-00-09/Report\%2003-00-092016.pdf (accessed 23rd December 2020).

Staveteig S, Wang S, Head SK, Bradley SE and Nybro E (2013) Demographic Patterns of HIV Testing Uptake in Sub-Saharan Africa. ICF International, Calverton, MD, pp. 39-47.

Stephenson R, Elfstrom KM and Winter A (2013). Community influences on married men's uptake of HIV testing in eight African countries. AIDS and Behavior 17(7), 2352-2366.

Sullivan MC, Rosen AO, Allen A, Benbella D, Camacho G, Cortopassi AC et al. (2020) Falling short of the First 90: HIV stigma and HIV testing research in the 90-90-90 Era. AIDS and Behavior 24(2), 357-362.

Sullivan PS, Carballo-Diéguez A, Coates T, Goodreau SM, McGowan I, Sanders EJ et al. (2012) Successes and challenges of HIV prevention in men who have sex with men. Lancet 380, 388-399.

Sylvester K, Braitstein P, Michael O, Ochieng OV, Daniel O, John S et al. (2010) Influence of gender on loss to follow-up in a large HIV treatment programme in western Kenya. Bulletin of World Health Organization 88(9), 641-716.

Treves-Kagan S, El Ayadi AM, Pettifor A, MacPhail C, Twine R, Maman S et al. (2017) Gender, HIV testing and stigma: the association of HIV testing behaviors and community-level and individual-level stigma in rural South Africa differ for men and women. AIDS and Behavior 21(9), 2579-2588. 
UNAIDS (2010) Global Report: UNAIDS Report on the Global AIDS Epidemic 2010. UNAIDS, Geneva, Switzerland.

UNAIDS (2014) Fast-track: Ending the AIDS Epidemic by 2030. UNAIDS/JC2686. 2014

UNAIDS (2015a) AIDS by the Numbers. UNAIDS, Geneva.

UNAIDS (2015b) Gap Report 2014. 2015. UNAIDS. URL: http://www.unaids.org/sites/default/files/media_asset/UNAIDS_ Gap_report_en.pdf (accessed 23rd December 2020).

UNAIDS (2017) Fact Sheet - Latest Global and Regional Statistics on the Status of the AIDS Epidemic. Joint United Nations Programme on HIV/AIDS (UNAIDS), Geneva, Switzerland.

UNAIDS (2018) Global HIV and AIDS Statistics - 2018 Fact Sheet. UNAIDS, Geneva. URL: https://www.hiv.gov/hiv-basics/ overview/data-and-trends/global-statistics (accessed 23rd December 2020).

UNAIDS (2019) UNAIDS 2019 Data. URL: https://www.unaids.org/sites/default/files/media_asset/2019-UNAIDS-data_en. pdf (accessed 23rd December 2020).)

Von Elm E, Altman DG, Egger M, Pocock SJ, Gøtzsche PC and Vandenbroucke JP (2007) The Strengthening the Reporting of Observational Studies in Epidemiology (STROBE) statement: guidelines for reporting observational studies. Annals of Internal Medicine 147(8), 573-577.

Waruiru W, Ngare C, Ssempijja V, Gachuki T, Njoroge I, Oluoch P and Kim AA (2014) The status of HIV testing and counseling in Kenya: results from a nationally representative population-based survey. Journal of Acquired Immune Deficiency Syndromes 66 (Supplement 1), S27.

WHO (2015) Global Health Observatory (GHO) Data. WHO, Geneva. URL: https://www.who.int/gho/hiv/en/ (accessed 23rd December 2020).

WHO, UNAIDS and UNICEF (2010) Scaling Up Priority HIV/AIDS Interventions in the Health Sector: Progress Report 2010. URL: http://www.who.int/hiv/pub/2010progressreport/report/en/index.html (accessed 23rd December 2020).

Wilson CM, Wright PF, Safrit JF and Rudy B (2011) Epidemiology of HIV infection and risk in adolescents and youth. Journal of Acquired Immune Deficiency Syndromes 54(1), 5.

Yao J, Agadjanian, V and Murray AT (2014) Spatial and social inequities in HIV testing utilization in the context of rapid scale-up of HIV/AIDS services in rural Mozambique. Health and Place 28, 133-141.

Ziraba AK, Madise NJ, Kimani JK, Oti S, Mgomella G, Matilu M et al. (2011) Determinants for HIV testing and counselling in Nairobi urban informal settlements. BMC Public Health 11(1), 663.

Cite this article: Budu E, Seidu A-A, Armah-Ansah EK, Mohammed A, Adu C, Ameyaw EK, and Ahinkorah BO (2022). What has comprehensive HIV/AIDS knowledge got to do with HIV testing among men in Kenya and Mozambique? Evidence from Demographic and Health Surveys. Journal of Biosocial Science 54, 558-571. https://doi.org/10.1017/ S0021932021000237 